Artigo recebido em

02/05/2014

Aprovado em

17/04/2015

Camila Mont'Alverne Universidade Federal do Ceará camilapessoa31@gmail.com Mestranda do Programa de Pós-Graduação em Comunicação da UFC. Integrante do Grupo de Pesquisa em Política e Novas Tecnologias (PONTE/ UFC). Bolsista Capes.

Francisco Paulo Jamil Marques

Universidade Federal do Ceará marquesjamil@gmail.com Professor e pesquisador permanente do PPGCOM/UFC. Bolsista de Produtividade em Pesquisa do CNPq. Realizou

Estágio Pós-Doutoral no PPGCOM/UFMG. Doutor e Mestre pelo PÓSCOM/UFBA. Líder do Grupo de Pesquisa em Política e Novas Tecnologias (PONTE/UFC).

${ }^{1}$ Uma versão anterior deste trabalho foi apresentada no II Congresso Mundial de Comunicação Ibero-americana (CONFIBERCOM), realizado em Braga, Portugal, no período de 13 a 16 de abril de 2014. Os autores são gratos à CAPES e ao CNPq pelos auxilios que tornaram a realização da pesquisa possível.

Estudos em Jornalismo e Mídia Vol. $12 \mathrm{~N}^{\circ} 1$ Janeiro a Junho de 2015 ISSN: 1984-6924

\section{A opinião da empresa no Jornalismo Brasileiro: Um estudo sobre a função e a influência política dos editoriais $^{1}$}

\section{Camila Mont'Alverne e Francisco Paulo Jamil Marques}

\begin{abstract}
Resumo
O objetivo do trabalho é refletir acerca do Editorial como elemento que, além de posicionar a instituição jornalística no campo social - ao revelar os valores e as perspectivas por ela defendidos e ao estabelecer um "contrato de leitura" com a audiência -, permite compreender de que maneira o Jornalismo brasileiro se diferencia daquele praticado em outros países cuja cultura profissional naturaliza a tomada de posição política por parte das empresas. Por meio de revisão bibliográfica, o artigo traz uma breve contextualização da trajetória do Jornalismo Opinativo no Brasil, além de discutir as características do Editorial como gênero. Em seguida, examinam-se as singularidades dos textos editoriais enquanto artifícios de ação política.
\end{abstract}

\section{Palavras-chave}

Jornalismo, Editoriais, Teorias do Jornalismo, Notícia, Política.

\begin{abstract}
The article examines the Editorials as an element that, beyond positioning the journalistic institution in the social field - by revealing the very values that it advocates -, enables us to understand how the Brazilian Journalism differs from the ones verified in other countries. The text brings a brief context of the path of opinionated Journalism in Brazil. Moreover, it discusses the characteristics of the editorial as a journalistic genre. Next, the article examines some of the editorials' singularities as a tool for political action.
\end{abstract}

\section{Keywords}

Journalism, Editorials, Theories of Journalism, News, Politics. 


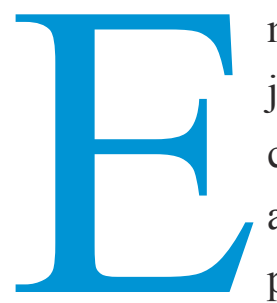

mbora as

empresas jornalísticas - em sintonia com aquilo que orienta a deontologia típica dos profissionais do campo

- se apresentem, frequentemente, como mediadoras neutras, objetivas e imparciais, sabe-se que o processo de coleta, elaboração e distribuição de conteúdos informacionais é influenciado, dentre outros elementos, pelos princípios, compromissos e interesses de cada agente com assento na cadeia produtiva das notícias (ABRAMO, 1997; KARAM, 1997).

Nesse sentido, a escolha das pautas e das fontes, dentre a adoção de outros procedimentos, pode servir para confirmar uma tese defendida pelo periódico. A existência de determinadas ênfases e enquadramentos direciona a cobertura planejada por editores e repórteres; podem ser verificadas, igualmente, variações no destaque conferido a cada matéria, seja em termos de espaço ou de tempo, ou ao se atribuir a determinado assunto o destaque como manchete principal (CONTI, 1999; LONGHI, 2006; SCHIFF, 2011).

Desta forma, as concepções de mundo do jornal se manifestam em diferentes oportunidades. Trata-se de uma opção feita não só pelo redator da matéria, mas, também, influenciada pela linha editorial e pelos interesses da empresa de comunicação (BARROS FILHO, 1995; TRAQUINA, 2005).

É inegável, assim, que o Jornalismo contribui para a construção da realidade, em vez de simplesmente refleti-la (FISHMAN, 1980; TRAQUINA, 2005; TUCHMAN, 1972). O estabelecimento de determinadas diretrizes no que concerne, por exemplo, à cobertura política (tema ao qual boa parte dos jornais dedica uma editoria específica), acaba por reverberar na forma pela qual se compreendem os agentes políticos e, consequentemente, nas imagens públicas que a audiência tem deles (GOMES, 2004).

Assim, por um lado, é necessário considerar que a construção do produto jornalístico se dá em um ambiente marcado por configurações bastante específicas, bem como está sujeita a pressões de diversos níveis (BENETTI, 2007). Por outro lado, é inegável que a ação dos jornais pode trazer contribuições à democracia, ao emplacar agendas que auxiliem em uma melhor administração do País, ou ao fiscalizar os agentes representativos.

O editorial, espaço opinativo reservado à instituição jornalística, no qual a empresa apresenta suas posições acerca de diversos assuntos, é, provavelmente, o gênero que melhor ilustra a tensão entre interesses públicos e privados no Jornalismo. Em outras palavras, o editorial se configura mais nitidamente como um espaço para o jornal "fazer política" e pressionar o poder público, além de ser uma forma de colocar assuntos na pauta coletiva de discussões (ARMAÑANZAS, NOCÍ, 1996; AZEVEDO, 2006; MELO, 1985). Dessa forma, os editoriais atuam não somente ao formatar traços da imagem pública - por exemplo, de agentes do campo político (BOURDIEU, 2011) -, mas, também, ao oferecer elementos que conformam a imagem do próprio jornal.

No Brasil, ainda são poucos os trabalhos dedicados a examinar, especificamente, a função e a influência política dos editoriais jornalísticos - não obstante ser este, justamente, um espaço capaz de revelar traços singulares da relação 
mantida entre as empresas jornalísticas e agentes do campo político.

Assim sendo, o trabalho ora apresentado tem como objetivo refletir acerca do Editorial como elemento que contribui para consolidar a posição social de determinada instituição jornalística ao revelar os valores e as perspectivas por ela defendidos e ao constituir o "contrato de leitura" (FAUSTO NETO, 2008) estabelecido com a audiência. Dentre os desdobramentos de tal debate, encontra-se uma breve discussão acerca de como o Jornalismo brasileiro se diferencia daquele praticado em outros países cuja cultura profissional naturaliza a tomada de posição política por parte das empresas.

A fim de alcançar tal meta, o texto foi dividido de acordo com os seguintes tópicos: "Notícia, Opinião e as tensões do campo do Jornalismo"; "A trajetória da Opinião no Jornalismo Brasileiro"; "Editorial: Quando o jornal toma partido"; "O papel político dos editoriais jornalísticos".

Notícia, Opinião e as tensões do campo do Jornalismo

Ao refletir acerca da natureza do produto jornalístico, várias distinções precisam ser feitas com o objetivo de se compreender o quão complexa se mostra uma atividade que envolve interesses públicos e privados, trabalhadores e empresas do campo da comunicação, concorrência por audiência e demais disputas simbólicas empreendidas por agentes internos e externos ao campo (BOURDIEU, 2011; SILVA, 2009).

Uma das distinções fundamentais se refere aos profissionais, de um lado, e às empresas que atuam no âmbito do
Jornalismo, de outro. Mencione-se, por exemplo, que os critérios utilizados para conferir prestígio por parte dos pares e as normas deontológicas de cada um desses agentes e instituições não necessariamente são iguais. Mesmo se considerarmos apenas os profissionais do jornalismo, percebe-se uma variação sensível no que se refere ao grau de liberdade de cada jornalista para emitir opiniões nos jornais.

Ainda que reconheça o universo de valores, prestígios, recompensas, punições, capitais e habitus, o argumento aqui delineado está mais preocupado em enfatizar três distinções cuja compreensão é essencial a fim de se fundamentar a discussão sobre o papel político dos editoriais.

a) As diferenças entre o setor comercial e a redação na empresa jornalística;

b) A separação entre notícia e opinião na cultura do Jornalismo moderno;

c) As marcas características dos gêneros e formatos jornalísticos, que sustentam a diferenciação entre reportagem, coluna, crônica, nota, dentre outros elementos;

Logo abaixo, cada uma dessas dimensões é explorada.

a) As diferenças entre o setor comercial e a redação na empresa jornalística:

As empresas de comunicação não fazem uma mera mediação entre os agentes políticos e a audiência. Dotadas de interesses próprios, elas se constituem como instituições (COOK, 2005; KOVACH, ROSENSTIEL, 2004). A relação delas com o campo político e com o econômico - é permeada por tensões e acomodações, já que cada domínio detém um tipo de capital que interessa ao outro (GOMES, 2004). Por contarem com regras e códigos próprios, 
a submissão flagrante do campo do Jornalismo a outro campo social pode deslegitimar a instituição ou o jornalista responsável pelo conteúdo. Em outras palavras, infringir as regras do bom Jornalismo em nome de compromissos econômicos ou políticos, por exemplo, acarreta ônus à pessoa física e à pessoa jurídica, como a perda da credibilidade (MIGUEL, 2002).

É por isso que, para Eugenio Bucci (2000), deve haver uma completa separação entre a redação e o departamento comercial da empresa jornalística, de forma a tentar evitar que os interesses econômicos interfiram nas diretrizes de produção das informações. Marques, Miola e Siebra (2014, p. 4) lembram, no entanto, que tal separação não garante completa isenção, pois, "mesmo indiretamente, verifica-se a intromissão do departamento comercial quando uma pauta é 'derrubada' a fim de dar espaço a um anúncio de última hora".

b) A separação entre notícia e opinião na cultura do Jornalismo moderno:

É interessante perceber como a distinção entre notícia e opinião foi sendo construída historicamente e ideologicamente. Visando atingir uma parcela mais ampla da sociedade, algumas estratégias (a exemplo da divisão entre textos opinativos e informativos) foram adotadas pelos empresários envolvidos na produção de informações, sobretudo ao longo do século XIX (ARMAÑANZAS, NOCÍ, 1996).

Ademais, diante do surgimento inicial de outras atividades do campo da Comunicação, como a Publicidade e as Relações Públicas, o Jornalismo precisou se apresentar socialmente com algum grau de distinção para convencer a audiência de que estaria apto a oferecer um produto "independente", cuja função seria a de apresentar a realidade ao conhecimento do leitor, além de representá-lo (como órgão fiscalizador) perante os agentes políticos. A distinção entre opinião e informação, portanto, tem como objetivo dar à audiência a impressão de que o noticiário estaria isento de impressões dos repórteres ou da própria empresa. É exatamente ao defender a separação clara das seções opinativas que surgem princípios como a "objetividade", voltada para reforçar um sentimento de legitimidade do que é "narrado" pelos jornais (KAPLAN, 2012; MOTTA, 2005).

Isso significa que a norma deontológica a orientar a ação das empresas e dos profissionais do Jornalismo (abrindo espaço para que seja reivindicado por parte de tais agentes o papel de defensores do "interesse público") considera que as tomadas de posição devem ficar restritas à página de opinião (ALBUQUERQUE, 2000; COUTINHO, MIGUEL, 2007; BIROLI, MIGUEL, 2010 e 2012).

O Manual de Redação do jornal $O$ Estado de S. Paulo (s.d.) - um dos quality papers de maior circulação no Brasil -, por exemplo, indica como norma o estabelecimento de uma separação clara entre textos opinativos e noticiosos, alertando a seus colaboradores sobre a necessidade de, no processo de redação das notícias, não expor "opiniões, mas fatos, para que o leitor tire deles as próprias conclusões". O Manual da Folha de S. Paulo (1996), por sua vez, reforça a ideia de que o jornalista deve se abster de opinar ou emitir juízos de valor em notícias ou reportagens. "O jornalismo crítico não depende da opinião de quem 
escreve: o simples registro ou confronto de dados, informações e opiniões alheias pode ser muito mais contundente que a opinião de um jornalista."

$\mathrm{O}$ fato de os manuais estarem disponíveis para consulta não só por parte dos profissionais, mas também pelos leitores, expõe uma preocupação de aproximar o público da "cozinha" responsável pela produção do jornal, ainda que não fiquem evidentes as diferentes tensões existentes na redação.

A perspectiva de que o Jornalismo seria espelho da realidade é contraposta à ideia de que, mesmo nos casos onde não há manipulação deliberada que envolva a cobertura de um acontecimento, o jornalista e a empresa acabam optando por enxergar o fato de uma maneira peculiar, a partir de critérios ligados também, mas não apenas - a códigos e a práticas da atividade. Assim, a ideia de que separar a opinião de uma seção específica do jornal deixaria o texto noticioso "puro" vem sendo criticada ao longo das últimas décadas.

Moraes (2007, p. 1) argumenta que o Jornalismo tem opinião, independentemente dos gêneros opinativo ou informativo. Chaparro (2003), por sua vez, duvida da efetividade da divisão entre informação e opinião ao argumentar que uma paginação diferenciada dos textos não garante um relato purificado, livre de pontos de vista.

Questiona-se, ademais, não apenas a possibilidade de se alcançar uma efetiva separação entre opinião e notícia, mas a própria utilidade dessa fragmentação. Argumenta-se se o que o leitor espera do Jornalismo não seria justamente uma mescla entre notícia e opinião, no sentido de orientar a audiência acerca da interpretação de fenômenos da vida social, como ocorre em diversos blogs jornalísticos (BAILEY e MARQUES, 2012). O fato é que, mesmo diante de tais polêmicas e divergências ideológicas ou teóricas, textos com clara ênfase opinativa continuam a ter seu espaço assegurado. Para Beltrão (1980, p. 14), o jornal tem a obrigação de exercitar a opinião.

...ela é que valoriza e engrandece a atividade profissional, pois, quando expressa com honestidade e dignidade, com a reta sacralidade das ocorrências, se torna fator importante na opção da comunidade pelo mais seguro caminho à obtenção do bem-estar e da harmonia do corpo social.

O texto opinativo, portanto, é visto como uma forma de o jornal cumprir com seu dever junto ao leitor, oferecendo a ele um modo de compreender o mundo, em oposição ao conteúdo informativo, cuja função - pelo menos em princípio - seria apresentar a realidade, sem interferir nos fatos.

c) As marcas características dos gêneros e formatos jornalísticos, que fundamentam a diferenciação entre reportagem, coluna, crônica, nota, dentre outros elementos:

Uma terceira e necessária distinção se refere à questão dos gêneros dentro da dimensão informativa e da dimensão opinativa do Jornalismo. O estabelecimento de subgêneros é a forma de operacionalizar a separação entre informação e opinião e um modo de condicionar o profissional a escrever o 
texto a partir de regras pré-estabelecidas.

Dentre os próprios subgêneros opinativos, a intenção e a forma de construir o texto se diferenciam. No caso do editorial, busca-se uma impessoalidade na abordagem temática e nas estratégias de argumentação, uma vez que está em evidência a voz da empresa (ALVES FILHO, 2006). Mas ressalte-se que não se trata de uma divisão estanque: o texto opinativo pode se utilizar de recursos, a princípio, concernentes às produções informativas. "A maioria dos gêneros jornalísticos são complementares uns de outros. Como a notícia, gênero informativo por excelência, complementa a reportagem, do mesmo modo, os gêneros de opinião complementam a informação oferecida pelos gêneros informativos" (ESPINOSA, 2002, p. 225, tradução própria²).

Conforme dito anteriormente, a ênfase deste trabalho se dá sobre o gênero "Editorial", categoria do Jornalismo opinativo. Antes de abordar especificamente tal categoria, pretendese realizar um breve apanhado histórico acerca da trajetória da opinião no Jornalismo brasileiro, a fim oferecer uma visão mais ampla das mudanças pelas quais passou a cultura jornalística no país.

\section{A trajetória da opinião no Jornalismo} brasileiro

Embora produzido na Europa, o Correio Braziliense, criado em 1808, é reconhecido como o periódico que dá início à história da imprensa nacional. Quando a Corte Portuguesa deixou o País,

${ }^{2}$ Todas as traduções de citações em língua estrangeira são de responsabilidade dos autores. outros periódicos, como a Gazeta do Rio de Janeiro, passaram a ser editados no Brasil (LUSTOSA, 2003).

Com a Proclamação da República, os grupos jornalísticos se consolidam (MARTINS, 2008). A República Velha (1889-1930) conhece, assim, algumas modificações no padrão de atividades da imprensa brasileira. Embora os avanços tecnológicos tenham contribuído para que mais publicações entrassem em circulação, a época também foi marcada por uma relação conturbada com o governo. A censura e o aliciamento da imprensa se tornaram recursos utilizados com maior frequência (ELEUTÉRIO, 2008).

As articulações políticas a envolverem as empresas jornalísticas brasileiras se mantiveram nas primeiras décadas do século XX. O apoio a Getúlio Vargas em 1930 é prova dessa associação:

Ao se instalar no Palácio do Catete, o líder do movimento que depôs Washington Luiz contava com os aplausos dos vários jornais de Assis Chateubriand, do Correio da Manhã, O Globo, Jornal do Commercio, Diário Carioca, Diário de Notícias, O Estado de S. Paulo, A Platéia e Diário Nacional, para mencionar alguns dos títulos mais importantes do país (LUCA, 2008, p. 166, grifo da autora).

No entanto, o clima amistoso não durou muito. Em 1932, muitos periódicos apoiaram a campanha em prol da redemocratização do Brasil e acabaram tendo suas sedes depredadas, a exemplo do jornal Diário Carioca (LIRA NETO, 2013; LUCA, 2008).

Com a convocação da Assembleia Constituinte, no entanto, os ânimos arrefeceram, ainda que provisoriamente. O Estado Novo, período que se estendeu de 1937 a 1945, instaurou o Departamento de Imprensa e Propaganda (DIP), que passou a ser o órgão responsável por subordinar os meios de comunicação de 
massa ao Governo (LUCA, 2008).

Nos anos seguintes à deposição de Vargas, a imprensa se encontraria polarizada entre os jornais Tribuna da Imprensa, de Carlos Lacerda, e Última Hora, de Samuel Wainer. Aliás, Wainer foi um dos principais responsáveis por trazer Getúlio de volta à cena política nacional, o que permitiu ao ex-presidente lançar nova candidatura para concorrer às eleições de 1950. Lacerda, por sua vez, usava a Tribuna da Imprensa para se opor ao ex-presidente (LAURENZA, 2008). Os dois periódicos perdem força com a instauração da ditadura militar.

Em 1964, a maioria dos grandes jornais brasileiros apoiou o golpe, embora alguns tenham mudado de posição com o recrudescimento do regime (LAURENZA, 2008; SODRÉ, 1999). Um dos periódicos envolvidos na derrubada do governo de João Goulart foi O Estado de S. Paulo, ainda que, anos depois, tenha passado à oposição $(\mathrm{O}$ Estado de S. Paulo, 2013).

Movimento semelhante fez a Folha de S. Paulo, que também se mostrou favorável à deposição de Jango e mantevese próxima à ditadura até meados dos anos 80 , quando aderiu à campanha das “Diretas Já!” (DIAS, 2012). O grupo Diários Associados, comandado por Assis Chateubriand, aprovou a deposição de João Goulart (LAURENZA, 2008), assim como o Jornal O Globo, que, recentemente, publicou um editorial no qual assume que errou ao apoiar a ditadura ${ }^{3}$.

As grandes publicações brasileiras adotaram posições discordantes em relação às "Diretas Já!", um dos acontecimentos de destaque no país durante a década de 1980. A Folha de
S. Paulo foi uma das poucas empresas a endossar o movimento desde o começo. Até o comício na Praça da Sé de São Paulo, que levou a campanha às ruas, as "Diretas Já!" eram acompanhadas com desconfiança por parte do Estadão e das revistas Istoé e Veja (PILAGALLO, 2012).

Na primeira eleição após o período de redemocratização, o Estadão publicou editorial em apoio à candidatura de Fernando Collor. O mesmo jornal, assim como a Folha, publicaria, em 1992, editoriais pedindo a renúncia do então presidente (PILAGALLO, 2012). No decorrer da década de 1990 e nos anos 2000, o Estadão continuou explicitando quem era o candidato que apoiava à Presidência, prática que não foi acompanhada por outros quality papers brasileiros. A Folha, em algumas ocasiões, endossou candidaturas, como a de Marta Suplicy à Prefeitura de São Paulo, em 2000, embora fizesse questão de reafirmar que tem compromisso com o leitor, não com grupos políticos ${ }^{4}$.

É importante ter em mente que, quando subscrevem determinado movimento ou candidatura, os jornais assumem que suas posições políticas não são aleatórias ou desinteressadas. "Endossos são atos políticos conscientes. Como tais, revelam a orientação política da imprensa" (ANSOLABEHERE et al, 2006, p. 394).

Dentre os vários gêneros opinativos existentes, no próximo tópico aprofundase o estudo do editorial.

\section{Editorial: quando o jornal toma partido}

É no texto editorial que o jornal - de forma explícita - sai de uma condição de imparcialidade (reivindicada na seção
${ }^{3}$ Disponivel em $<$ http://oglobo.globo. com/pais/apoio-editorial-ao-golpe-de-64-foi-um-erro-9771604>. Acesso em 28 nov. 2013.

${ }^{4}$ Disponível em <http://wwwl.folha. uol.com.br/fsp/opiniao/fz1510200001. htm > . Acesso em 2 dez 2013. 
de notícias) e assume ter posições acerca dos mais diversos temas de concernência pública. Em outras palavras, é por meio do editorial que:

... o grupo proprietário e administrador do periódico manifesta sua opinião sobre os fatos que se desenrolam em todos os setores de importância e interesse para a comunidade e ligados à existência e desenvolvimento da empresa, intentando, desse modo, orientar o pensamento social para a ação na defesa do bem comum. $\mathrm{O}$ editorial é a voz do jornal, sua tribuna (BELTRÃO, 1980, p. 51-52).

Assim, o teor dos editoriais está intrinsecamente ligado aos princípios defendidos pelo periódico, que são "as linhas mestras que marcam ideologicamente os conteúdos jornalísticos e fundamentam a atividade empresarial de uma publicação" (ARMAÑANZAS, NOCÍ, 1996, p. 171). Beltrão (1980) afirma que a política editorial não é arbitrária: na verdade, ela obedece a princípios éticos e a normas práticas, não sendo apenas definidas por questões comerciais.

Armañanzas e Nocí (1996, p. 102), por sua vez, veem o editorial como um conselheiro dos leitores, que buscariam opiniões atualizadas sobre temas diversos. “(...) o periódico está comprometido a dizer o que pensa e o leitor espera uma orientação". O editorial, assim, aprofunda questões tratadas nas notícias, ou pode até ir além delas (BELTRÃO, 1980), pautando a própria cobertura. "Com o posicionamento acerca da atualidade, o jornal vai construir, a cada dia, uma visão de mundo. É importante tratar o editorial ainda como um espaço de formação da opinião pública, porque atua na tematização do debate" (MORAES, 2007, p. 3). José Marques de Melo (1985, p. 80) complementa tal raciocínio:

A leitura de editoriais dos jornais diários, por exemplo, inspira-nos a compreensão de que as instituições jornalísticas procuram dizer aos dirigentes do aparelho burocrático do Estado como gostariam de orientar os assuntos públicos. E não se trata de uma atitude voltada para perceber as reivindicações da coletividade e expressá-las a quem de direito. Significa muito mais um trabalho de "coação" ao Estado para a defesa de interesses dos segmentos empresariais e financeiros que representam.

Assim, os editoriais, pela característica de serem porta-vozes da opinião da empresa, têm um peso diferenciado na publicação. Não é à toa que ocupam um espaço privilegiado na diagramação dos jornais - e, eventualmente, nos telejornais - e são escritos, normalmente, por profissionais experientes, que devem "estar perfeitamente ao par do pensamento e objetivo do grupo empresarial" (BELTRÃO, 1980, p. 59).

O editorial, além de oferecer opinião, é um agente da voz e do conteúdo do jornal. Mais que produzir opiniões, ele representa o conteúdo total do periódico; ele coloca em domínio público assuntos, eventos e ideias para consumo e discussão 
em um fórum democrático (HALLOCK, 2007, p. 162).

Porsetratardeumgênero institucional, o editorial não é assinado (BELTRÃO, 1980). De acordo com Moraes (2007), tal característica dá um tom de autoridade às opiniões manifestadas. A estrutura argumentativa do editorial busca o convencimento de que o tema apresentado é relevante e importante de ser discutido. Ou seja, os editoriais podem ser, também, um chamado à ação. "De maneira progressiva, vão-se publicando escalonadamente uma série de editoriais sobre um mesmo tema, até chegar a pedir uma ação concreta. São muito frequentes em períodos eleitorais" (ARMAÑANZAS, NOCÍ, 1996, p. 95).

Os editoriais procuram conferir, portanto, um tom de verdade aos próprios temas e às posições adotadas: "o que se busca é que ele [o leitor] aceite a orientação argumentativa apresentada e, consequentemente, alinhe-se à posição enunciativa defendida pelo jornal" (ALVES FILHO, 2006, p. 87).

Mesmo diante das referências apresentadas até o momento neste trabalho, considera-se haver uma literatura ainda escassa especificamente sobre os editoriais. Provavelmente, a carência de discussões e estudos mais aprofundados acerca de tal gênero jornalístico em âmbito nacional se deve ao seguinte fato: no Brasil, não é comum os periódicos tomarem partido de forma explícita (MORAES, 2007). Ou seja, além do baixo número de leitores de jornais ${ }^{5}$, no cenário brasileiro, os periódicos não costumam tomar partido ao defender uma candidatura específica,

por exemplo, à Presidência.

A apresentação das preferências poderia ser útil para o leitor se orientar não só no que concerne às questões debatidas pelos editoriais, mas, também, em relação ao próprio jornal, uma vez que seria possível saber melhor quais os interesses intrínsecos do produto ofertado à audiência. No caso brasileiro, o Estadão é exceção ao tradicionalmente expor suas posições. Em outros países, como na Espanha, "o periódico que renuncia a mostrar abertamente sua linha editorial constitui uma exceção" (ARMAÑANZAS, NOCÍ, 1996, p. 87).

Há de se destacar, então, a influência de fatores que caracterizam a cultura jornalística de diferentes países. Em trabalho que aborda o modo através do qual os conceitos de corrupção e clientelismo são examinados pela literatura em Comunicação e Política, Albuquerque e Pinto (2013) identificam diferenças entre as culturas jornalísticas de acordo com o lugar, exemplificando tal fenômeno a partir das distintas relações entre jornalistas e fontes.

Ainda em um mesmo país, a cultura jornalística pode ser diferente de acordo com a região. A importância e o formato dado ao editorial nos jornais pode ser exemplo disso. Alves Filho (2006) identifica o caso do jornal Diário do Povo, em Teresina, no qual alguns editoriais apresentavam a estrutura de notícias. No caso da realidade espanhola, Castilla e Gross (2009) encontraram uma variação em relação à página ocupada pelo texto enquadrado em tal gênero. Hallock (2007) identifica, por sua vez, diferenças e semelhanças em relação à temática dos assuntos discutidos pelos editoriais em diversos
${ }^{5} \mathrm{O}$ trabalho de Azevedo (2006) traz dados sobre hábitos de leitura. Em pesquisa realizada na Grande São Paulo, verifica-se que em torno de $35 \%$ dos indivíduos leem regularmente. Outra pesquisa, também apresentada no trabalho, e de abrangência nacional, aponta queda no índice de leitura diária de jornais de acordo com o quanto decresce a classe socioeconômica. Em um cenário em que um índice maior que 100 significa que as pessoas são mais propensas a ler jornais diários do que a população geral e que menor que 100 significa o contrário, nas classes A e B, ele é de 180. Na $C, 89$ e, nas classes $D e$ E, 38 . 
jornais dos Estados Unidos, de acordo com a competição mercadológica à qual estavam submetidos e com a região do país à qual pertenciam.

As diferenças de posicionamento ou de abordagem não diminuem, porém, o peso político dos editoriais, que permanecem sendo "a opinião mais autorizada que o periódico oferece sobre a interpretação da notícia" (ESPINOSA, 2002, p. 232). Ao serem o elemento de identificação ideológica de uma empresa de comunicação (ESPINOSA, 2002), eles estão ligados diretamente à função política que esta tem na sociedade. No próximo tópico, o artigo analisa o papel político dos editoriais.

\section{O papel político dos editoriais jornalísticos}

No tópico anterior, discutiu-se uma das principais funções políticas dos editoriais: orientar e convocar o leitor à ação. Porém, deve-se ressaltar que mesmo este "chamamento" realizado pelos jornais tem um limite. Por exemplo, os editoriais não costumam problematizar as estruturas mais fundamentais do sistema político. Coutinho e Miguel (2007), em estudo sobre a Crise do Mensalão nos editoriais de periódicos brasileiros, sugerem que, por mais que a cobertura midiática possa ter contribuído para inflar o escândalo - colocando-o em pauta diariamente e apresentando os "culpados" -, não há um maior questionamento acerca das bases do sistema da política democrática.

Desta forma, pode-se dizer que o editorial acaba trabalhando com uma concepção naturalizada do que é política e de como as ações políticas se desenrolam. Diagnosticar a concepção naturalizada de política exposta pelo
Jornalismo, contudo, não exime a instituição de uma ação partidária. Tal fenômeno é verificável quando as empresas manifestam "ativamente - e não apenas em posições conjunturais ou disputas eleitorais - uma posição política situada. O Jornalismo é a expressão de uma parte nas disputas mesmo quando não existe alinhamento político-partidário estável ou que funcione como motor para as "mensagens"” (BIROLI, 2012, p. 5). Isso significa que o Jornalismo reforça os limites da política na medida em que os consagra e os naturaliza.

Por outro lado, pode-se questionar o quanto a ideia de política (em sentido amplo) adotada pelo Jornalismo - e, consequentemente, pelos editoriais está influenciada pela concepção que os cidadãos têm do termo. Ansolabehere et al. (2006, p. 396), por exemplo, afirmam que, ao longo dos últimos 60 anos, a ênfase da cobertura dos jornais americanos deixou de ser o partido e passou a ser o candidato.

Com o passar do tempo, no entanto, os endossos ficaram mais focados em candidatos individuais. Os jornais detalhavam as razões para apoiar cada candidato. [...] Essa tendência sugere que os editorialistas deslocaram $\mathrm{o}$ foco no partido para o foco em características pessoais do candidato, inclusive o fato de já terem algum cargo.

Tal fenômeno pode estar ligado às próprias mudanças na política verificadas durante o Século XX, com os partidos perdendo força e as campanhas tornando- 
se mais personalizadas (ADAM, MAIER, 2010), além do aumento da oferta de informação. O Jornalismo, por mais que influencie no modo de se fazer política, não define sozinho o que é entendido como tal, e tem de se adequar às expectativas da audiência.

Os editoriais jornalísticos também procuram cumprir o papel de fiscalizar os agentes políticos e se posicionam como um representante do leitor. $\mathrm{O}$ fato de apresentarem discordâncias e críticas ao governo também pode ser creditado à busca por cumprir tal função, além da tentativa de influenciar as políticas públicas (IZADI, SAGHAYE-BIRIA, 2007).

Uma perspectiva ainda pouco explorada na literatura brasileira aproxima o campo do Jornalismo e suas instituições aos partidos políticos e às associações de grupos de interesses, ou seja, à sociedade civil (COOK, 2011). Percebe-se, no caso, uma crítica ao fato de que as empresas jornalísticas dependem do Estado em alguns sentidos, ainda que disponham de um capital fundamental (a visibilidade) ao qual outras instâncias da sociedade não têm acesso com facilidade. A afirmação do autor reforça a tensão na atuação das empresas de comunicação, que são instituições privadas investidas de legitimidade para atuar em nome do público.

A importância do texto editorial se mostra, ainda, na definição da agenda - não só em sugerir o que será objeto de discussão, mas ao enquadrar os parâmetros de abordagem das questões de interesse coletivo. "Escritores de editoriais têm desenhado o apelo de suas páginas em direção a propósitos que incluem ter voz em estabelecer agendas sociais e em um debate político robusto, num vívido e democrático mercado de ideias" (HALLOCK, 2007, p. 22).

$\mathrm{O}$ enquadramento dado a determinadas questões pode influenciar os limites do debate, além de aumentar a responsabilidade do governo perante a audiência (COOK, 2005), situação na qual o jornal pode pressionar os agentes representativos para alcançar os objetivos delineados.

Hallock (2007, p. 138) entrevistou editores de jornais dos EUA a fim de descobrir, dentre outras coisas, a importância que os jornalistas conferem ao texto editorial. A resposta de um deles indica que os profissionais têm noção da influência da qual dispõem perante a audiência e aos agentes políticos. Mais que isso: consideram importante utilizar-se dela. " $\mathrm{Eu}$ acredito profundamente que os editoriais são um elemento central do mercado de ideias. Comentários fundamentados escritos por pessoas informadas podem - e devem - ajudar a estabelecer os parâmetros do debate"”.

Em pesquisa sobre editoriais de jornais dos EUA na época da invasão ao Afeganistão, em 2001, Billeaudeaux et al. (2003) ressaltaram a importância de os políticos conseguirem o apoio dos jornais em editoriais, pois estes funcionam como gatekeepers e como definidores dos assuntos que estarão na agenda dos media. No caso, os pesquisadores encontraram forte reverberação do discurso do governo nos editoriais, ainda que isso possa ter acontecido por ser um contexto singular. Também em pesquisa sobre editoriais de jornais americanos quando da ação 
militar no Afeganistão, Ryan (2004, p 380) identifica um endosso às posições do governo e uma crítica à atuação das empresas de comunicação. "Escritores de editoriais não só falharam em desafiar as visões oficiais, também as endossaram e legitimaram."

Em relação à cobertura e aos personagens envolvidos, é verdade que há atores fiscalizados com mais afinco ou enquadrados de forma predominantemente negativa, mas não se pode descartar o fato de determinadas regras de funcionamento do Jornalismo também serem responsáveis por limitar a pluralidade dos enquadramentos presentes nos produtos (COOK, 2005).

A legitimidade da qual dispõe o campo do Jornalismo se evidencia não apenas quando se confere autoridade a determinadas fontes, mas também durante o processo de seleção do que será alvo de cobertura e a partir de quais parâmetros. Os temas abordados pelos editoriais indicam o que a publicação acredita ser o assunto de maior relevância naquele dia - e um estudo dos temas discutidos pode esclarecer quais questões o jornal acredita serem as de maior destaque.

“A função do editorial como intérprete autorizado da atualidade se exerce não só no enfoque concedido ao tema, mas também na própria seleção do mesmo como elemento destacado da atualidade" (OROSA et al., 2013, p. 487). Os autores citados argumentam que as empresas de comunicação tendem a priorizar a abordagem de assuntos nos quais possam ter sua opinião levada em conta, como questões de política interna. Ao comportar-se assim, o periódico passa a exercer função de agente político, tentando usar do poder do qual dispõe
Ao mesmo tempo, pelo fato de a rotina jornalística estar sujeita a certos critérios que interferem na configuração do produto, nem sempre a empresa pode escolher os assuntos que vai destacar de acordo com a conveniência deles ao jornal.

Em determinados dias, no entanto, acontecimentos tais como um discurso do Rei, um atentado etc, exigirão do meio resposta à situação através de um editorial. Esta é uma condição cujo cumprimento é obrigatório, pois aquelas publicações que, sistematicamente, tratem de evitar sua responsabilidade social, dedicando seus editoriais a temas relativamente intranscendentes ou de escassa controvérsia social, para assim evitarem problemas com algum setor, acabaram sendo atacados e menosprezados por essa atitude (ESPINOSA, 2002, p. 233-234).

Sendo assim, a empresa tem de lidar com uma situação ambígua: se pode utilizar-se do respaldo do qual dispõe perante a audiência para oferecer um ponto de vista e pressionar os agentes políticos em direção às posições que julga mais adequadas, também precisa lidar com as cobranças inerentes à prática do Jornalismo, sob pena de comprometer a credibilidade, caso as desconsidere.

Ainda que o texto opinativo não esteja necessariamente sujeito à busca pela imparcialidade e objetividade, a concepção acerca do que deve ter destaque na cobertura costuma ser compartilhada pelos agentes do campo do Jornalismo. Enquanto pode usar de seu capital social para pressionar os agentes políticos, a empresa tem de lidar com a necessidade de oferecer à audiência um produto que atenda a determinadas 
expectativas, exprimindo uma tensão entre os interesses privados e coletivos presentes na configuração do produto jornalístico.

A partir da leitura, reflexão e crítica de um conjunto relevante de referências dedicadas a investigar o Jornalismo brasileiro, defende-se que a concepção que as empresas têm acerca dos editoriais caracteriza o próprio modo através do qual elas acreditam exercer sua função social. Mais que isso, o próprio texto é uma forma de a empresa colocar em prática a função que acredita cumprir, ao usar do poder de pressão do qual dispõe junto aos atores políticos e, ao mesmo tempo, oferecer à audiência um quadro interpretativo para compreender a realidade.

\section{Conclusão}

Explorou-se, neste trabalho, a importância política do editorial, tanto em relação à posição que a empresa de comunicação se coloca perante a audiência, quanto para os agentes políticos. Ademais, puderam ser discutidas questões mais abrangentes sobre Jornalismo e Política e do editorial como gênero, abrindo espaço para a abordagem de um objeto que não é fartamente pesquisado no Brasil.

Sabe-se que é através do editorial que o periódico realiza sua própria política, ao comentar e emitir juízos sobre as práticas da democracia e acerca de outros temas. É comum que os periódicos se coloquem, por meio dos editoriais, como portadores do discurso da verdade, defendendo suas posições, citando autoridades científicas e discutindo políticas públicas a partir de indicadores aceitos como confiáveis (PINTO, 2006). Albuquerque (2000) aponta, inclusive, que, no caso do brasileiro, as publicações procuram ocupar o espaço de "Poder Moderador".

A concepção de que os editoriais atuariam como conselheiros ou guias dos leitores dialoga com a legitimidade da qual as empresas jornalísticas se investem para arbitrar questões de cunho coletivo. Em suma, argumenta-se que o papel político dos editoriais estaria ligado à função que os próprios jornais acreditam cumprir na realidade brasileira.

O editorial também demonstra a existência de uma tensão permanente nos periódicos: quando a empresa admite ter suas opiniões - e, consequentemente, não ser um mediador desinteressado -, a isenção de sua cobertura se torna passível de questionamento. Uma vez que a empresa jornalística não é um agente "neutro", deve-se levar em conta que, da mesma forma que ela pode se alinhar e defender as medidas governamentais que julga adequadas, ela também pode cobrar providências por parte do poder público.

Em um negócio que lida com o interesse coletivo, afirmando representálo, tal posição é delicada, pois coloca em risco a credibilidade do periódico, uma vez que ele passe - ou aparente passar - a defender interesses privados, o que pode ferir o contrato com o leitor. Ao funcionar de acordo com uma lógica própria, a seleção dos enquadramentos é feita de acordo com os critérios de noticiabilidade e a necessidade de acumular atenção da audiência sem elevar os custos para isso, ao invés de levar em conta as necessidades dos atores políticos ou o tipo de mensagens das quais as pessoas precisam, enquanto 
cidadãos (STRÖMBÄCK, VAN AELST, 2013).

Os editoriais podem dizer muito sobre a cobertura informativa da empresa de comunicação, que chega a um público mais amplo. Quais são as influências da opinião da instituição sobre a cobertura noticiosa é algo a ser investigado com maior profundidade. No entanto, os editoriais passam por um dilema ainda maior, pois não podem se utilizar de estratégias como a objetividade para justificar os enquadramentos apresentados, obrigando o jornal a trazer para si a responsabilidade das caracterizações e das opiniões em foco, ao invés de atribuí-las a uma suposta reflexão da realidade.

Referências bibliográficas

ABRAMO, C. A Regra do Jogo: o jornalismo e a ética do marceneiro. São Paulo: Companhia das Letras, 1997.

ADAM S.; MAIER M. Personalization of politics: A critical review and agenda for research. In: Salmon, C. (ed.) Communication Yearbook 34. London: Routledge, 2010, p. 213-257.

ALBUQUERQUE, A. Um outro quarto poder: jornalismo e responsabilidade política no Brasil. Contracampo, Rio de Janeiro, v. 4, p. 23-57, 2000.

.; PINTO, P. O inferno são os outros: Mídia, Clientelismo e Corrupção. Disponível em < http://www.compos.org.br/data/biblioteca_2009.pdf > . Acesso em 16 dez 2013.

ALVES FILHO, F. A autoria institucional nos editoriais de jornais. Alfa, São Paulo, v. $50, \mathrm{n}^{\circ} 1, \mathrm{p} .77-89,2006$.

ANSOLABEHERE, S. et al. The Orientation of Newspaper Endorsements in U.S. Elections, 1940-2002, Quarterly Journal of Political Science, nº 1, p. 393-404, 2006.

ARMAÑANZAS, E.; NOCÍ, J. D. Periodismo y argumentación. Géneros de opinión. Universidad del País Vasco, 1996.

AZEVEDO, F. A. Mídia e democracia no Brasil: relações entre o sistema de mídia e o sistema político. Opinião Pública, Campinas, v. 12, nº 1, p. 88-113, 2006.

BAILEY, O; MARQUES, F. P. J. A. Brazilian News Blogs and Mainstream News Organizations: tensions, symbiosis, or independency?. In: SIAPERA, E; VEGLIS, A (Org.). The Handbook of Global Online Journalism. West Sussex: Willey-Blackwell, v. 1, 2010. p. 395-411.

BARROS FILHO, C. Ética na Comunicação: de informação ao receptor. São Paulo: Moderna, 1995.

BELTRÃO, L. Jornalismo opinativo. Porto Alegre: Sulina, 1980.

BENETTI, M. A ironia como estratégia discursiva da revista Veja. Líbero, São Paulo, v. 20, p. 14-26, 2007. 
BILLEAUDEAUX, A. et al. Newspaper editorials follow lead of Bush administration. Newspaper Research Journal, EUA, v. 24, n 1, p. 166-184, 2003.

BIROLI, F. O jornalismo como gestor de consensos: limites do conflito na política e na mídia. Disponível em <http://bit.ly/1fEdT1L>. Acesso em 7 jun 2012.

.; MIGUEL, L. F. A produção da imparcialidade: A construção do discurso universal a partir da perspectiva jornalística. Revista Brasileira de Ciências Sociais, São Paulo, v. 25, nº 73, p. 59-76, 2010.

$\therefore$ . Orgulho e preconceito: a "objetividade" como mediadora entre o jornalismo e seu público. Opinião Pública, Campinas, v. 18, nº 1, p. 22-43, 2012.

BOURDIEU, P. O campo político. Revista Brasileira de Ciência Política, Brasília, n5, p. 193-216, 2011.

BUCCI, E. Sobre ética e imprensa. São Paulo: Companhia das Letras, 2000.

CASTILLA, E. B.; GROSS, T. L. Identidad editorial en la prensa nacional española: interrelación con la agenda mediática. Revista Latina de Comunicación Social, La Laguna (Espanha), v. 12, n 64, p. 602-611, 2009.

CHAPARRO, M. C. Jornalismo não se divide em opinião e informação. Disponível em $<$ http://tinyurl.com/ak362mk >. Acesso em 6 mai 2012.

CONTI, M. S. Notícias do Planalto - a imprensa e Fernando Collor. São Paulo: Companhia das Letras, 1999.

COOK, T. E. Governing with the news. Chicago: The University of Chicago Press, 2005.

. O jornalismo político. Revista Brasileira de Ciência Política, Brasília, n. 6, p.

203-247, 2011.

COUTINHO, A.; MIGUEL, L. F.. A crise e suas fronteiras: oito meses de mensalão nos editoriais dos jornais. Opinião Pública, Campinas, v. 13, p. 97-123, 2007.

DIAS, A. B. O presente da memória: Usos do passado e as (re) construções de identidade da Folha de S. Paulo, entre o 'golpe de 1964' e a 'ditabranda'. 2012. 204f. Dissertação (Mestrado em Comunicação). Setor de Ciências Humanas, Letras e Artes, Universidade Federal do Paraná, Curitiba.

ELEUTÉRIO, M. L. Imprensa a serviço do progresso. In: LUCA, T. R.; MARTINS, A. L. (Org.). História da imprensa no Brasil. São Paulo: Contexto, 2008.

ESPINOSA, P. M. Géneros para la persuasión en prensa: los editoriales del Diario El País. Ámbitos, Sevilla (Espanha), nº 9-10, p. 225-238, 2002.

Estadão.com.br. Conheça o jornal. Disponível em $<$ http://bit.ly/1hkfYuZ>. Acesso em 27 mar 2013.

FAUSTO NETO, A. Fragmentos de uma “analítica” da midiatização”. Revista Matrizes. 
São Paulo, ano 1, n 1, 2007, p. 89-105.

FISHMAN, M. Manufacturing the news. Austin: University of Texas Press. 1980.

IZADI, F.; SAGHAYE-BIRIA, H.. A Discourse Analysis of Elite American Newspaper Editorials: The Case of Iran's Nuclear Program. Journal of Communication Inquiry, v. 31, nº 2, p. 140-165, 2007.

GOMES, W. Transformações da política na era da comunicação de massa. São Paulo: Paulus, 2004.

HALLOCK, S. M. Editorial and Opinion. Praeger, Westport, 2007.

KAPLAN, R.. The origins of objectivity in American Journalism. In: ALLAN, S. (Org.). The Routledge Companion to News and Journalism. New York: Routledge. 2012. p. 25-37.

KARAM, F. J. Jornalismo, Ética e Liberdade. São Paulo: Summus, 1997.

KOVACH, B.; ROSENSTIEL, T. Os elementos do jornalismo. São Paulo: Geração Editorial, 2004.

LAURENZA, A. M. A. Batalhas em letra de forma: Chatô, Wainer e Lacerda. In: LUCA, T. R.; MARTINS, A. L. (Org.). História da imprensa no Brasil. São Paulo: Contexto, 2008 .

LIRA NETO, T. Getúlio - 1930-1945: Do governo provisório à ditadura do Estado Novo. São Paulo: Companhia das Letras, 2013.

LONGHI, R. Opinião e diagramação. Estudos em Jornalismo e Mídia, Vol. III No 1, pp. 110-119, 2006.

LUCA, T. R.; MARTINS, A. L. (Org.). História da imprensa no Brasil. São Paulo: Contexto, 2008.

LUSTOSA, I. O nascimento da imprensa brasileira. Rio de Janeiro: Zahar, 2004.

Manual de redação e estilo. Instruções gerais. Disponível em <http://www.estadao. com.br/manualredacao/gerais.shtm>. Acesso em $24 \mathrm{dez} 2012$.

Manual de Redação da Folha de S. Paulo. Verbetes letra “O”. Disponível em < http:// www1.folha.uol.com.br/folha/circulo/manual_texto_o.htm>. Acesso em 26 abr 2014.

MARQUES, F. P. J. A.; MIOLA, E.; SIEBRA, N. Jornalismo, assessoria de imprensa e seus condicionantes organizacionais: Uma reflexão a partir das Teorias do Jornalismo. Animus (Santa Maria. Online), v. 13, p. 145-166, 2014.

MARTINS, A. L. Imprensa em Tempos de Império.In: ; LUCA, T. R.(Org.). História da imprensa no Brasil. São Paulo: Contexto, 2008.

MELO, J. M. A opinião no jornalismo brasileiro. Petrópolis: Vozes, 1985. MIGUEL, L. F. Meios de comunicação de massa e política no Brasil. Diálogos Latinoamericanos, Aarhus (Dinamarca), v. 3, p. 43-70, 2002. 
MORAES, C. H. de. Parcialidade alardeada: notas sobre a importância da opinião no jornalismo. Disponível em <http://tinyurl.com/ad48hhe>. Acesso em 6 mai 2012.

MOTTA, L. G. A Análise Pragmática da Narrativa Jornalística. In: CONGRESSO BRASILEIRO DE CIÊNCIAS DA COMUNICAÇÃO, 28., 2005. Rio de Janeiro. Anais... São Paulo: Intercom, 2005. CD-ROM.

OROSA et al.. Análisis de la adaptación a la red en los editoriales on line de cinco países europeos. Revista Latina de Comunicación Social, La Laguna (Espanha), nº 68, p. 485-501, 2013.

PILAGALLO, O. História da imprensa paulista: Jornalismo e poder de D. Pedro I a Dilma. São Paulo: Três estrelas, 2012.

PINTO, C. R. J. Elementos para uma análise de discurso político. Barbarói, Santa Cruz do Sul, v. 24, p. 87$118,2006$.

RYAN, M.. Framing the war against terrorism: US Newspaper Editorials and Military Action in Afghanistan. Gazette, Londres (Inglaterra), v. 66, nº 5, p. 363-382, 2004.

SCHIFF, F. Framing the President: The dominant ideology - A comprehensive repertoire of news frames. Contemporanea, Salvador, v. 9, $\mathrm{n}^{\circ} 1,2011$.

SILVA, G. De que campo do jornalismo estamos falando? Revista Matrizes, São Paulo, ano 3, n 1, p. 197-212, 2009.

SODRÉ, N. W. História da imprensa no Brasil. Rio de Janeiro: Mauad, 1999.

STRÖMBÄCK, J.; VAN AELST, P. Why political parties adapt to the media: Exploring the fourth dimension of mediatization. International Communication Gazette, v. 75, nº 4, p. 341-358, 2013.

TRAQUINA, N. Teorias do Jornalismo, por que as notícias são como são. Florianópolis: Insular, 2005.

TUCHMAN, G.. Objectivity as Strategic Ritual: An Examination of Newsmen's Notions of Objectivity. The American Journal of Sociology, v. 77, n 4, p. 660-679, 1972.

Estudos em Jornalismo e Mídia está sob a licença Creative Commons 2.5 